$<$ fresh recto $>$

$<\mathrm{RH}(\mathrm{L})$ : Kevin Dahan $>$

$<\mathrm{RH}(\mathrm{R}):$ A Temporal Framework for Electroacoustic Music Exploration $>$

<footer: Organised Sound 25(2): 000-000 (C Cambridge University Press 2020.>

\title{
A Temporal Framework for Electroacoustic Music Exploration
}

\section{KEVIN DAHAN}

Music, Technology and Innovation - Institute for Sonic Creativity $\left(\mathrm{MTI}^{2}\right)$, De Montfort University, Leicester Email: kdahan@dmu.ac.uk

Many aural analytical methods have been produced for electroacoustic music that focus on the identification of salient morphological features of the sounds. Doing so, they usually overlook the importance of time - a central aspect of music - sometimes by considering it as a simple compositional parameter. However, this article proposes a novel theoretical framework for electroacoustic music understanding by putting time and its cognitive representations during perception at the forefront. Two concepts are introduced to propose this alternative approach to electroacoustic music description: temporal directionality, which focuses on the sounds themselves, and temporal distancing, which focuses on the relations between sounds. Throughout this article, several musical examples are given to briefly exemplify how such concepts can be used in an explanatory context. Finally, polychrony is introduced, which aims to describe how electroacoustic composers play with the various cases of temporal directionality and distancing, and, in the process, actually weave time itself.

\section{INTRODUCTION}

The evolution of Western music, like most human activities, can be thought of as a long process of emancipation from our physical, perceptual and cognitive limitations, at the centre of which lies the shifting concept of time, ${ }^{1}$ through the medium of tools. This trajectory has been explored in anthropology since the works of Leroi-Gourhan (Leroi-Gourhan 1966), and

1 This is the subject of a book currently being completed by the author entitled The Technology of Time. In this article, I will not discuss at length or in much detail non-electroacoustic music. Therefore, the current article could be viewed as a sort of prologue. 
more recent developments have integrated digital technology in their analytical apparatus as well (Stiegler 2018).

Quite interestingly, composers have always been using and devising constraints as part of their composition processes, and sometimes as the sole reason for their compositions: from Philippe de Vitry's motets, to Johann Sebastian Bach's Art of Fugue, to Pierre Boulez's Sonates, to Pete Stollery's Onset/Offset, to Ryoji Ikeda's Dataplex, music has always thrived when composers have devised rules from themselves dictating the boundaries of what could be done or used in their compositions. It should not be surprising: it has long been the view that, to make sounds into music, sounds have to be structured and organised. What is more efficient and more straightforward therefore than to use 'arbitrary' constraints to limit the range of possibilities? These constraints are of different natures, linked to a specific music idiom or not; of varying complexity, simple or cumulative; addressing what materials could be employed, and how they could be used, modified and transformed. Yet, in one way or another, they are designed to deal with the fundamental problem composers face: hierarchical organisation. Whether in terms of pitches, rhythms, harmonies or timbre, composers have almost all been concerned with the actualisation of their works - their projection in time - so much that hierarchical organisation often singularly equates to temporal organisation. 2

From the point of view of musicology however, addressing the question of temporal organisation never appeared to be central. Most analytical strategies developed after Riemann described classification of pitch and harmony, as in Schenkerian analysis (Schenker 1935) or focusing on melodic organisation, such as in Allen Forte's pitch set theory (Forte 1973). More recently, the generative theory of Fred Lerdahl and Ray Jackendoff (Lerdahl and Jackendoff 1983) or Dmitri Tymoczko's geometrical models to 'extended common practice' (Tymoczko 2011) use comparable approaches, based on successive analytical reductions of the original musical material. By nature, such reductions use a range of established symbolic representation systems, which explain in part why they almost exclusively address Western musical systems from $c .1600$ onwards. In non-tonal, as in non-Western traditions, the topic of time is often equated to the study of rhythms (Arom 1985) with some considerations on the philosophical conceptions of time underlying music theories (Clayton 1996, 2008). In other words, it is quite safe to follow Kramer, more than thirty years after the publication of The

\footnotetext{
${ }^{2}$ This is especially true in the teleological context of Western music tonality (Meyer 1967: esp. ch. 5).
} 
Time of Music, and note that 'musical time is not usually considered a subject of music theory at all' (Kramer 1988: 2).

Of all the forms of music that have emerged over the last century or so, electroacoustic music $^{3}$ represents a particular case: it encompasses a wide variety of very different things, so that its semantics are the subject of seemingly endless debates. ${ }^{4}$ The successive disruptions that occurred over the last 150 years, enabled by the advances in technologies, from refinement in manufacturing in the nineteenth- to twenty-first-century machine learning and big data, mean, however, that musical works composed in these times all share a common trait. They have been composed using techniques that allow different (and finer) manipulations of temporal musical structures, from greater control possibilities in traditional musical instruments due to advances in instrument building to microsecond sample placement in current digital audio workstations. All this, in turn, have had a deep impact on how they are perceived, and how we engage with them, as analysts or 'simple' listeners.

Because of the multitude of hierarchical structures now possible to enact, it is quite common to explain the various times and temporalities that coexist in and through these works by characterising them to be either physical (i.e., quantifiable, static) or subjective (i.e., qualitative, in motion) (Kramer 1993). This article posits that, while there is merit in these categories, such a take is usually oversimplifying and ultimately results in a dead end. Instead, it proposes an approach registering the multiple and concurrent nature of time in electroacoustic works, as well as the perspective of the listener (called soundpoint in this text), through first, an examination of the notions of temporal directionality, and second of temporal distancing. Finally, the concept of polychrony is described.

\section{TEMPORAL DIRECTIONALITY}

3 I use this term, for lack of a better one, in its widest sense, as in 'music created through the conversion of acoustic to electric energy or vice-versa': there is no stylistic implication. Electronic music is too restrictive, acousmatic too connoted, and electroacoustic musics is simply insufferable. I will also use 'sound-based music' to designate an even larger body of works, when the production of sounds is not dependent on the conversion of electric energy. So, music $>$ sound-based music $>$ electroacoustic music. Electroacoustic music is therefore used here as a subset of sound-based music that embraces the many different uses of post-electrical technology.

4 Quite understandably (and most of the time, reassuringly) so. 
In a previous article on the topic of compositional processes (Dahan 2009), I broadly defined temporal directionality as a conceptual device used to describe any temporal aspects of musical structures (physical, subjective, potential, actual). This concept was, at the time, an attempt at refining Xenakis's concepts of in-time and outside-time (Xenakis 1963) to cater for improvisational and traditional compositional practices within a single analytical framework. Thus, it was rooted in a formal (and somewhat teleological) view of music and, while useful, reclaimed further tinkering in order to be operational for an even wider range of musical settings, including, crucially, sound-based music. Of course, in this context, of paramount importance is the listener, whose position is often overlooked in either musicological analyses or theoretical texts on compositional practices. This is still paradoxically largely true - even in a field where the importance of perception is constantly underlined in most academic texts.

\subsection{Directionality and cognition}

Epistemologically, sound-based music presents a significant challenge, since works may not make use of any pre-agreed, formal, and structural grammar or logic to organise their construction, instead largely opting for a percept-based architecture. This holds true for all sound-based music of course, but there is a supplementary dimension to current electroacoustic music, in light of its reliance on digital technology, since this opens up the possibility for the composer to create an exo-perceptual5 cohesion - hidden to even the most acute listener - through the elaborate use of complex processes (e.g., networks of algorithms, multidimensional objects, non-linear manipulations). It may be contested that this argument is still valid for other, more traditional, composition techniques - however, the focus shift from notes to sounds is significant enough to make the comparison shallow, ${ }^{6}$ as it significantly augments the density of structural information. Serialism would be the most evident example: while a trained listener can identify a series of twelve notes and its permutations, s/he already

${ }^{5}$ The Greek prefix 'exo-' means outer, external. This is different from 'non-perceptual': in our context, nonperceptual would mean isolated, separated from perception, whereas exo-perceptual recognise and register the existence of a perceptual system, but deliberately operates out of it. One could perhaps describe Gottfried Michael Koenig's Project 1 composition software as 'non-perceptual', contrasting with John Chowning's algorithmic compositional software used for Stria as 'exo-perceptual' (Dahan 2007).

6 Even in the case of 'classical' computer music, where pitches are still definite, clearly discernible and constitute an essential part of the compositional fabric, sounds are of equal importance structurally. 
has difficulties in doing the same for rhythms and/or articulations (Ockelford and Sergeant 2013); so, the serialist artificial construction of timbre seems even more out of bounds for auditory perception. ${ }^{7}$

Therein lies one of the many difficulties faced by electroacoustic music: ultimately, its understanding (and perhaps appreciation) compels the listener to devise an elaborate description of the cognitive processes at play during the perception of a sonic event, while at the same time being 'grounded' in it. This is something that may be facilitated (or not) by the composer (i.e., the 'something to hold on to' factor (Landy 1994)). Of course, these processes take place concurrently, in 'real-time': it is their conjugation and coexistence that forms the basis of the concept of temporal directionality.

Let us come back to our initial concept of temporal directionality. As I mentioned, while practical in analytical contexts (it permits one to analyse an algorithmic composition and/or a free improvisation using the same tools), the original version of the concept failed to register the many levels of temporal structuration that are exhibited in sound-based and electroacoustic music. Moreover, since it was partly based on Xenakis's views on time, it rested upon the classical binary opposition between cyclicality and linearity ${ }^{8}$ (Xenakis 1997), and therefore failed to take into account the multiple avatars of time in current sound-based and electroacoustic music, from the strange elasticity of drone textures, down to the subtly shifting morphologies of microsound aggregates. But how to accommodate such drastic dimensional changes?

This is where a concept developed over a century ago comes to the rescue. It has been posited by McTaggart (1908) that events can be ordered in two main different ways: the 'series of positions running from the far past through the near past to the present, and then from the present to the near future and the far future', which he calls the A-series, and the 'series of positions which runs from earlier to later', the B-series. He later (McTaggart 1927:

7 Including that of the composer as well, as exemplified in Stockhausen's early elektronische Musik Studien.

8 It is also not uncommon in texts that mention time in electroacoustic music to find an offspring of this initial dichotomy: there are various names, but it revolves around the opposition between a 'physical' and a 'psychological' time. There is, of course, merit and a certain validity in this approach, but here I strive to keep such opposition at bay as much as possible. 
355) supplemented this with the C-series 'which goes in the direction from less inclusive to more inclusive'.

A possible analogy to grasp most aspects of McTaggart's series is to consider a list of notes. The B-series is constituted by reading the notes in any order (left to right, right to left, or any other possibility): the resulting output would be a series of notes ordered by an 'earlier than/later than' order, not registering any change from one note to the other: this order is fixed 'as is' forever. Using the same direction, the sequence of notes could be read sequentially using a cursor, with the notes placed on one side of the cursor called 'past', the notes on the other side 'future', and the cursor labelled 'present'. The order created by this process now depends on the position of the cursor: it registers change and is tensed - creating the A-series. Finally, the C-series is actually the sequence of notes in the given order - which has no existence in time, but can be related to each other through their content.

This conception of time as an abstract construct is especially useful in our context: based on 'cognitive states' it could therefore be used, quite literally, to provide a characterisation of the various states of mind experienced while subjected (listening) to sound-based music. One of the seductive aspects of McTaggart's theory is that there is absolutely no prescription whatsoever on the size of events, which is indeed especially convenient ${ }^{9}$ for the study of electroacoustic music (and, in particular, its more recent developments).

It is important to stress that temporal directionality examines the endogenous characteristics of sound units. It means that aspects of a sound unit's morphological features (in the broadest sense) have a direct incidence on how a listener is going to process the sonic information, shaping up specific cases of temporal directionality. In essence, temporal directionality is a method for describing the listener's timeflow. I therefore expanded my original concept to cater for three cases of temporal directionality - intrinsic, extrinsic and peripheral - which would be applicable regardless of the size of the element considered.

\subsection{Intrinsic temporal directionality}

9 It also has the merit of being distinct from Bergson's conceptions, which are commonly found in musicological texts: the two philosophers are diametrically opposed on their views on time (unreal for McTaggart, real and continuous for Bergson). 
What is intrinsic temporal directionality? To keep in line with McTaggart's series, it can be understood as the series of sonic elements (or units10) that appear to flow inclusively from one to the other (i.e., they cannot be 'inverted'), and, as such, each element appear 'tensed' much as in the grammatical ${ }^{11}$ sense: intrinsic temporal directionality is a direct exemplification of McTaggart's A-series. To put it slightly differently, the respective position of the sonic time-slices determines a history (hence it can only make sense when examined linearly and sequentially). Or, to express it again in another way, there is a convergence of the A-series in music with the well-known concepts of memory (past), perception (present) and expectation (future).

Quite interestingly (and unsurprisingly), many sound-based music works extensively use intrinsic temporal directionality: it directly addresses the listener's immediate perception. In electroacoustic music this is especially true in the case of works in the 'acousmatic' tradition - it could be argued that this style could be the music exemplification of what represents the extreme position of some tenants of the A-series, presentists: only the present has an existence, and it translates as an extreme emphasis on perception. It is not entirely surprising that most studies in music psychology tend to exhibit an A-series bias, as they often focus on perception, which is anchored in the 'now' (and of course accounting for memory and expectation). This idea is also close to Bergson's concept of pure duration (Bergson 1922), and it is hard to refrain from quoting in extenso this passage:

Listen to a melody with your eyes closed, thinking of it alone, no longer juxtaposing on paper or an imaginary keyboard notes which you thus preserved one for the other, which then agreed to become simultaneous and renounced their fluidity in time to congeal in space: you will then rediscover, undivided and indivisible, the melody or part of the melody that you will have replaced within pure duration. 12

First, it is striking that Bergson uses music as the prime example to explain his concept of pure duration, and there are obvious ties to phenomenology here. Second, the similarities

\footnotetext{
10 The concept of sonic unit will be discussed in section 4.1 .
}

11 These concepts are not developed with any semantic or linguistic bias.

12 'Écoutez la mélodie en fermant les yeux, en ne pensant qu'à elle, en ne juxtaposant plus sur un papier ou sur un clavier imaginaires les notes que vous conserviez ainsi l'une pour l'autre, qui acceptaient alors de devenir simultanées et renonçaient à leur continuité de fluidité dans le temps pour se congeler dans l'espace: vous retrouverez indivisée, indivisible, la mélodie ou la portion de mélodie que vous aurez replacée dans la durée pure' (Bergson 1922 [2007]: 47). 
with Pierre Schaeffer's reduced listening posture, inherited from phenomenology, are no less striking. By way of consequence, it appears that musique concrète and 'traditional' acousmatic music, given their reliance on Schaeffer's principles, frequently make use of intrinsic temporal directionality.

Therefore, examples of intrinsic temporal directionality are numerous in works from composers of the acousmatic tradition. Bernard Parmegiani's seminal suite De Natura Sonorum operates almost wholly at this level: many of the movements are explicitly based on 'simple' oppositions (e.g., Incidences/Résonances, Accidents/Harmoniques, Pleins et déliés), which suggests to the listener to focus on the current sounds with some reliance on memory and expectation (through the movement titles), but with both relegated to the background during the listening. A similar device can be found in Francois Bayle's 'Le bleu du ciel', the fourth movement of Espaces Inhabitables: the sonic units are constructed using samples from a piano and a zither, clearly identifiable, and therefore linked to a memory (past). These sonic units further exhibit intrinsic temporal directionality, playing with the listener's expectation (future) by describing a melody $\left(10^{\prime} 57^{\prime \prime}-11^{\prime} 07^{\prime \prime}\right)$, before explicitly guiding the listener's attention towards the immediate experience (present) of their multiple endogenous characteristics (resonance, pitched, unpitched, harmonic texture and so on). The whole movement is an exceptionally subtle exercise in the use of sonic units for their intrinsic temporal directionality values. 13

\subsection{Extrinsic temporal directionality}

Extrinsic temporal directionality, conversely, implies that sonic units do not follow the preceding inclusive and tensed logic (e.g., sonic units could be permuted, reversed or shuffled without impacting the continuity of timeflow). Taken individually, they appear 'tenseless', again in the grammatical sense: to this respect, it corresponds to McTaggart's B-series. In this case, the position of sonic time-slices only determines a collection (i.e., there are multiple possible orders depending on 'arbitrary' external criteria).

Thinkers who consider the B-series as the essential aspect of time are called eternalists. In music, of course, there is a strong link between this particular stance and the Western notated music tradition: after all, most of the developments from the Renaissance and

\footnotetext{
${ }^{13}$ Without jumping to any conclusion regarding the links between intrinsic temporal directionality and
} narrativity, it is worth noting that many compositions of Francois Bayle use some sort of narrative. 
Baroque era until the twentieth century have been strategies for organising notes - essentially symbolic representations on paper (and therefore, musical information abstracted from time) extracting most of the 'tensed' aspects of sounds.

The principle of extrinsic temporal directionality is especially interesting for contemporary music theory as it could be understood in some ways as a generalisation of Stockhausen's concept of Momentform (Stockhausen 1963). The original concept stresses the importance of considering a given moment without any relation to the previous or next ones, extending to a sort of 'timelessness' (Zeitlosigkeit), and was written to explain the compositional procedures used in Kontakte. While there is some flexibility related to the 'duration' of a moment, the concept is generally used to describe relatively large sections of compositions, whose proportions are often calculated before deciding on the music (Kramer 1978: 182). In the case of extrinsic temporal directionality, timelessness is not a 'consequence' of higher order structural decisions, but rather exist in the sonic unit themselves.

Consequently, in electroacoustic music, extrinsic temporal directionality is mostly found where sonic units have very little affordances. A good example of extrinsic temporal directionality is found in Gareth Loy's Nekyia: taken in isolation, the sonic units that make up the second section (from $2^{\prime} 04^{\prime \prime}$ to $4^{\prime} 30^{\prime \prime}$ ) are absolutely directionless - tenseless; nevertheless the listener is able to find grouping strategies based on the exogenous characteristics of sonic units (see the following section 3), and collections emerge, with an eventual resolution in the next section.

\subsection{Peripheral temporal directionality}

When sonic units relate both to an external and an inclusive logic, peripheral temporal directionality comes into play. Musically, this is, for example, what happens in techniques such as Klangfarbenmelodie: in such compositions, potentially tenseless elements (e.g., specific individual sounds) are unequivocally part of a tensed structure (e.g., a pitch in a melodic line). Again, it is important to stress that temporal directionalities are devoid of linguistic or semantic significations; therefore, peripheral directionality is different from a 'simple' double entendre. In a way, each sonic unit exhibit at least two clearly identified characteristics, the positions of which determine, in turn, two differentiated sets. As such, it can be seen as close to McTaggart's conception of the C-series, which is, essentially, a Bseries without any given temporal ordering. 
The musical version of the $\mathrm{C}$-series can therefore be thought of as untimed. Drawing a parallel with Xenakis's concept of 'outside-time' is tempting, but his definition is that of a rigid conceptual space in which the musical elements are devoid of existence in the 'present' (e.g., scales, logical or operational relations between notes) (Xenakis 1963). Peripheral temporal directionality, by contrast, also exists in time: the logic of inclusion of the C-series works especially well in the case of sonic units, whose endogenous characteristics are multiple and sometimes ambivalent.

This ambivalence is probably why peripheral temporal directionality is actually a very common trope in 'classical' computer music works (i.e., most American computer music from the 1970s and early 1980s), where the ambiguity on the exact nature of sonic units is sought by composers. The canonical example of the exploration of such tensions - and by way of consequence, of the C-series in electroacoustic music - is the famous opening of Jean-Claude Risset's Mutations: the similar frequency construction of the three initial sonic units of the piece - melody, chord, timbre - is well known (Risset 1996). Indeed, the diverse experimentations opened up by digital sound synthesis are excellent examples of peripheral temporal directionality: in Risset's Little Boy, the famous never-ending downward glissando of 'Fall'; the control over an ever expanding and contracting space in most of Chowning's compositions; more recently and in a different style the high-pitch/sub-bass artefacts in Kim Cascone's 'The Bourbaki Conjecture'.

In the wake of Stockhausen's initial experiments on tone mixtures, computer music gave rise to sounds that will not decide their states, being concurrently melody, chord, timbre, rhythm and space, giving way to multiple interpretations and reinterpretations by the listeners.

\subsection{Interpolation: is there causality in electroacoustic music?}

Electroacoustic music makes use of the various types of temporal directionality for sonic units - they can in turn be tensed (intrinsic temporal directionality/A-series), tenseless/timeless (extrinsic temporal directionality/B-series) or untimed (peripheral temporal directionality/Cseries). An important question that therefore arises - which I will leave open for further exploration elsewhere - is that of causality in electroacoustic music: from the soundpoint of the electroacoustic music explorer, does s/he experience causal links from one sonic unit to the other?

\section{TEMPORAL DISTANCING}


The concept of temporal directionality works nicely to examine endogenous characteristics of musical material, but is not sufficient to capture the interrelationships between different sonic units, whether they are articulated one to the other, or placed far apart - since these aspects are exogenous to the musical material (in) itself. This is where temporal distancing ${ }^{14}$ comes in to play - to shed light on what happens at the intersection, or between the interstices, of sonic units. From the listener's perspective, and during the reception of a sound-based musical work, they could be understood as the properties that bring us back to, or keep us away from, a particular sense of timeflow. As with temporal directionality, I propose three distinct cases of temporal distancing: attached, detached and surfaced.

These categories will, necessarily, appear to share some similarities with Emmerson's syntaxes (Emmerson 1986: 17-39). Both concepts are explanations of something similar - the layout of musical material in electroacoustic music: as it will be evidently clear in the following, one might consider mapping abstract syntax to attached distancing and abstracted syntax to detached distancing. However, the two concepts do not seek to describe exactly the same thing: while Emmerson is explicitly concerned about an examination of electroacoustic music as a language, temporal distancing seeks to characterise sonic units in relation to the listener's subjectivity, emotions, and - therefore(?) - sense of time. ${ }^{15}$

\subsection{Attached distancing}

One of the easiest ways to understand attached temporal distancing is to consider pulses. In many musical styles, steady pulses are grouped into rhythmic patterns, which are then resegmented ${ }^{16}$ into regular metres, which gives rise to nothing more than temporal signposts that guide the perception of the listener through a process known as entrainment (Patel 2008). They can also be thought of as the musical equivalent of marked indications on a map suggesting groupings, delineating structures and creating virtual boundaries between sonic units; as such, they usually require a legend, to summarise notation conventions. In electroacoustic and sound-based music (and more generally in most of post-WWII

14 The concept of distancing is loaded with signification. In this particular case, it is not dissimilar to Brecht's Verfremdungseffekt in many respects.

15 Susanne Langer's works on how art and feelings are connected through symbols are of particular interest here (Langer 1942).

16 Through repetition - a concept that is too broad to be fully developed here (Margulis 2014). 
contemporary music), there is little use of steady pulses - and going so far as to using (properly explicit) metres would probably be considered borderline heretic! ${ }^{17}$ This is a significant change: pulses and rhythmic cells are timekeeping elements that are usually played by percussion instruments in many musical traditions, from sub-Saharan polyrhythmic traditions, to Balinese gamelan, Indian rāg and disco music. As such, there is a strong link between the notion of pulses and body (especially since they are usually expressed through gestures) 18 - and with what it is culturally and traditionally associated: physical reality. It is also quite clear that even in their 'empty shells' incarnation as electronic 'beats' in electronic dance music, pulses are still very much linked to corporality and embodiment. An interesting and startling example can be found in 33EMYBW's self-defined 'limb dance' approach. This link to a physical reality - however distant and irregular it may be - and hence to a measurable, quantifiable, grounded and shared (or to put it differently, a reassuring) sense of time is the gateway to understanding attached temporal distancing.

Let us now eschew the term 'reality' (which would have drawn us towards musical ontology) and use 'coherence' instead. It is quite evident that musical works (whether they are compositions, improvisations or anything in between) are arranged according to particular orders, whether these are defined by composers, performers, or traditions. Furthermore, because of the specificities of sound-based music, electroacoustic music compositions are usually self-contained - and sometimes self-referential (i.e., there is a specific and unique coherence that gets established for and within each piece $\left.{ }^{19}\right)$. Hence, from the soundpoint of a listener (and particularly an inexperienced one), the coherence that arises during the experience of a composition is external - that is, it corresponds to the logic imposed by the work itself.

The efforts deployed to bring the listener closer to this 'external' coherence constitute the real crux of attached temporal distancing. There are two main compositional strategies: (a) the

${ }^{17}$ It is very probably another reason why electroacoustic music has difficulties reaching out to new audiences. Continuing the previous analogy, one can but wonder whether the absence of pulses is a symptom or a consequence of the absence of cartographic conventions for electroacoustic music.

18 This link has been often explored by Steve Reich, almost in these terms (see notably Clapping Music, Drumming, Pulse).

19 That does not mean there is no stylistic similarities among the works of a single composer, but rather that there are no established rules to follow to gain coherence. 
use of rhythmic cues, such as electronic beats, repetitions of simple rhythmic cells, recurrences of percussion-like sounds; and (b) the exploitation of mimetic sonic units that provide sufficient affordances for the listener to relate to a minimal common experience, such as sound samples of natural ${ }^{20}$ origins - biological (e.g., heartbeats) or ecological (e.g., wind, waves). The main goal here is to ensure an anchor for the listener's perception into the coherence of the musical work (which is therefore initially external to the listener) - part of what Landy calls the 'something to hold on to factor'. Of course, accustomisation - and therefore memory - also plays an important part on how 'attached' a listener will be.

In electroacoustic music, the most obvious examples of attached distancing is found in modern hybridised genres, such as electronica and IDM; more often than not, works in these genres rely on a good amount of repetitions (notably of rhythmic cells) - enough to make it embodied, not sufficient to render it danceable - to guide the listeners in their otherworldly aesthetics. This is what happens, for example, in Autechre's 'Theme of a sudden roundabout': there is very little, if any, literal repetition in this composition, but since the bubbly quality of the sounds is echoed in the curvature of the many asymmetric rhythmic cells, the listener is never left alone to figure out the coherence of the piece. The processes that make attached distancing particularly effective in this work can be perceived quite clearly (they are especially abundant) from $1^{\prime} 30^{\prime \prime}$ to $2^{\prime} 07^{\prime \prime}$. Attached distancing strategies can also be found in works where the sonic units used are very complex and extremely diverse, and consequently risk overwhelming the listener. This is what happens in Trevor Wishart's Globalalia; for example, the rhythmic texture from $0{ }^{\prime} 45^{\prime \prime}$ to $0^{\prime} 57^{\prime \prime}$, or the function of the 'voice signal' at $24^{\prime} 10^{\prime \prime}, 24^{\prime} 20^{\prime \prime}, 24^{\prime} 30^{\prime \prime}, 24^{\prime} 45^{\prime \prime}, 24^{\prime} 55^{\prime \prime}, 25^{\prime} 05^{\prime \prime}$ and $25^{\prime} 15^{\prime \prime}$ - these are simple cues in an ocean of complexity.

\subsection{Detached distancing}

On the other hand, instead of providing the listener with an aural lifeline, detached temporal distancing seeks to keep the listener as far away from registering any external coherence as possible, instead 'forcing' him/her to retreat into or develop his/her own personal, 'internal', subjective coherence, or interpretation. This does not go against the exo-perceptual organisation of the musical work: the goal is not to unearth the compositional techniques from aural perception, but rather to characterise the elusive nature of time in sound-based and

20 The fact that they can be mere simulacra is not relevant in this context. 
electroacoustic music. The techniques that can be used for this are multiple and diverse, but the general compositional strategy is to render things as irregular and unpredictable as possible - increasing noise and entropy. This can be achieved in many ways; for example, by a densification of the information space or the elaboration of a barren rhythmic landscape. It may echo the familiar Boulez's notion of temps lisse (smooth time) (Boulez 1968) - but all the same, it should be recalled that Boulez's focus in this text is notated music and therefore symbols.

In electroacoustic music, detached distancing moments are relatively frequent: it is quite easy to generate noise and noisy elements using the electronic instrumentarium. One good example is the beginning of Vladimir Ussachevsky's Linear Contrasts - but note the progression of the composition introducing successively regular drum-like sounds (from 0'50"), and melodic elements played in loops (from 1'36"). James Dashow's Sequence Symbols also uses many compositional devices to keep the listener puzzled; the entire composition is an exploration of a synthetic timbre space but eschewing the melodic continuity usually found in other works in this vein (e.g., Chowning's Stria) in favour of a succession of varied oppositions.

\subsection{Surfaced distancing}

The ability to make internal and external temporal coherences coexist seamlessly has long been a goal for composers: the entire history of Western music might be viewed as a constant search for technological tools to help make such transitions as fluid as possible. Surfaced temporal distancing happens at pivotal moments in compositions, when internal and external coherences nearly juxtapose: explained differently, the organisation of sonic units in the work allows the listener to be grounded in its musical coherence, while at the same time there is sufficient entropy not to enclose him/her in a single interpretation. It is important to note that while internal and external coherences can overlap, this does not imply the communication of any meaning: in the realm of electroacoustic music, the consensus on semiotics has not yet been reached (Atkinson 2007).

Many early computer music compositions are prime examples of surfaced distancing. This is the case in Michael McNabb's Dreamsong - in which the voice and vocal sounds are always questioned - from $4^{\prime} 00^{\prime \prime}$ to $4^{\prime} 30^{\prime \prime}$ and the transition from soprano colorature to basso profundo, or the Dylan Thomas's speech initially blurred and ultimately incomplete from $8^{\prime} 30^{\prime \prime}$. Such ambiguity is also quite frequent in compositions using granular synthesis, as 
exemplified in Horacio Vaggione's Harrison Variations, in which granular textures regularly coalesce into artificially crafted sound samples (e.g., 6'30" seq.).

\subsection{Interpolation: is there such a thing as quantum sound?}

The question of the relations across temporal directionality and distancing is difficult to avoid. Temporal directionality concerns the endogenous characteristics of sonic units (put differently, it examines the features of a sonic unit considered in isolation), while temporal distancing addresses exogenous aspects (i.e., the dynamics of sonic units put together). These are examined from the soundpoint of the listener, which means that perception (and other components of a perceptual system - memory, expectation (Huron 1996)) is essential. This observed tension between features and dynamics echoes the well-known Heisenberg's uncertainty principle of quantum physics: we cannot precisely predict both the position and the momentum of a given particle. Furthermore, in the case of electroacoustic music, which can address all aspects of temporal directionality and distancing through digital tools, and in which the position of the observer is central, another question springs to mind - which I also voluntarily leave open: when we listen to electroacoustic music, are we examining quantum sounds?

\section{POLYCHRONY}

The previous sections demonstrated that temporal directionality and temporal distancing are concepts that operate simultaneously across various organisational levels, or, to use terminology from Vaggione (2001) and Roads (2015), at varying timescales - their ability to deftly use microscopic sound elements to generate contrasting sound objects and textures is one of the hallmarks of their composing styles. In Roads's latest classification, there are nine different timescales, ranging from 'infinite' to 'infinitesimal', with 'sound object' at the centre (fifth scale). This, of course, implies that composers have the ability to control sonic units and organise sound structures at every level, something which has only recently been unlocked through the medium of digital technology. Rather than thinking in terms of timescales, I propose to characterise how different times simultaneously coexist within a work; this explains why I introduced a different and flexible concept as the basic sonic block in my attempt at describing a temporal framework for electroacoustic music understanding: the sonic unit.

\subsection{What are sonic units?}


Throughout the description of both temporal directionality and temporal distancing, the term 'sonic unit' was used, but no precise definition was given. In truth, this is a very simple concept: it merely designates a sonic element that can be taken and examined in isolation, regardless of its originating temporal or organisational level. It follows that, from a single grain of sound (e.g., 1/100th of a second) to a whole texture (e.g., 100+ seconds), anything can be considered a sonic unit. A useful analogy is that of time-slices, the sizes of which can differ. Inevitably, their content will vary accordingly, but what happens if we are to consider each of these as a single, self-contained, basic entity? All we are left with are nuggets of information, which we are free to examine as we see fit. Since our goal is to find new ways of accounting for the multidimensionality of time as experienced in electroacoustic music - and not to establish an operative compositional theory - it is important to stay as neutral as possible. Interestingly, very recent research in neurosciences tend to suggest that auditory perception is based on adaptive auditory sampling, working at different timescales, as several experiments 'found a considerable variation in the best sampling frequency for each individual participant ... suggesting that these can vary across a considerable range' (Kayser 2019). If these results are confirmed in other studies, that would be an interesting step towards establishing a quantitative approach to temporal directionality and distancing.

Hence, sonic units have the merits of being self-contained, adaptive and formless - much like our auditory perception, as it seems. So much that, in fact, I initially used the term 'lexeme' to designate such elements - however, in an effort to move further away from linguistic considerations, I finally opted for the more neutral - albeit perhaps more cumbersome - terminology of 'sonic unit'. ${ }^{21}$ What settled the debate was the idea of density. It does not matter whether a sonic unit is 'long' or 'short', since the important aspect is the quantity of perceptual information that it provides - therefore a sonic unit can be very short if it is packed with perceptual 'data' and very long if the information is minimal (or if the information is constantly repeated, resulting in a longer sonic unit - such as an ostinato). There is no need for a quantitative scale - as it allows the concept to account for differences across listeners (e.g., musical expertise, listening experience of a particular genre, listening angle).

21 And this was only after toying with many other concepts and labels: sonic bits, sonic quanta, sound shreds, sonic slices - some of which may or may not be developed in the future! 


\subsection{But why 'sonic units'?}

At this point of the discussion, it might be useful to address the main differences between the concept of sonic unit and some 'classical' approaches of electroacoustic music theory.

Why not use Schaeffer's seminal concept of sound object? Because a sound object, in Schaeffer's theory (Schaeffer 1966), has many prescriptions, but most importantly, it is strongly dependent on the posture of reduced listening. Consequently, (a) it does not exist per se (i.e., a sound object is not self-contained); (b) while it is described as an unit of sound, this description is deeply rooted in a phenomenological view of music, which somehow evacuates extra-perceptual considerations (an aspect which may seem paradoxical given the purported operational nature of the treatise); and (c) there are strong links with ideas of Gestalt, and notably the idea of a form.

Then what is the difference with Smalley's spectromorphology? Spectromorphology (Smalley 1997) is in many ways an extension and a refinement of Schaeffer's initial conceptualisation of sound objects and typomorphology. There is a clearer dichotomy in Smalley's approach between the spectral information, viewed as structural and inherently instantaneous, frozen in time (spectro-), and its temporal developments, dynamic and evolving by nature (-morphology). Smalley's theory easily lends itself to being used operationally, in an analytical setting, but also for composition (Blackburn 2011), which is not the case of what is developed in this article.

Or with the 'Temporal Semiotic Units'? The 'Temporal Semiotic Units' (UST, for Unités Sémiotiques Temporelles) have been developed since the early 1990s as tools for music analysis and pedagogy (Delalande 1996). Registering the limitations of Schaeffer's initial sound object concept, the USTs attempt to reconcile morphological considerations with semantic meaning by creating a catalogue of nineteen archetypes (e.g., chute, qui tourne, freinage), based on structural characteristics (duration, repetition, number of phases, sound matter). There is clear merit in this approach, particularly from a pedagogical standpoint; however, as I strived to be as neutral as possible, the clear semantic/analogy approach taken by USTs was equally out of bounds.

\subsection{Weaving time}

Using such a neutral concept for elaborating a theoretical framework helps the electroacoustic explorer develop a unique perspective in sound-based and electroacoustic music for its understanding and analysis, but also provides interesting insights into the compositional 
processes. Since I established that sonic units could be understood as units of sonic information of varying density, it is therefore possible to take the next step and consider sonic units as units of sonic information exhibiting different kinds of temporal directionality and temporal distancing, containing different times, and henceforth we are dealing with polychrony.

Polychrony happens when multiple times are juxtaposed and superimposed. The result is similar in many ways as to what polyphony is for melodies (an amalgamation of several different techniques for grouping and leading voices). Polychrony is a compound, made of the various types of temporal directionality (that describe sonic units in themselves) and temporal distancing (that characterise the relations between sonic units) being brought together by the composer. In the same way that baroque composers used to weave voices, the contemporary electroacoustic composers now weave time itself.

Polychrony is the latest evolution of compositional techniques. This technique has clearly been unlocked by the prevalence of digital technology in electroacoustic music composition and in sound editing - by allowing composers to work and operate at the sample level, should they wish to. ${ }^{22}$ It is tempting to see granular synthesis composition techniques as the primary example of polychrony. While it is true that many of the compositions made by 'microsound' composers (Horacio Vaggione, Curtis Roads, Mario Mary and so on) typically exemplifies polychrony, it is broader than that: going back to our initial concepts, compositions using extensively both intrinsic and extrinsic temporal directionality would fall under this category. One such example is William Schottstaedt's Dinosaur Music: the initial section (up to 0'45") alternates sonic units of varying directionality and duration. These oppositions and juxtapositions are used throughout the work, in the process using rhythmic pulses to reinforced attached temporal distancing aspects (1'57" and 2'00", then $2^{\prime} 57^{\prime \prime}$ seq.). The penultimate section restates the initial polychrony ( $5^{\prime} 23^{\prime \prime}$ seq.), which is further expanded in the conclusion by using a very long sonic unit $\left(6^{\prime} 00^{\prime \prime}\right.$ seq.), then a series of very short and dense sonic units as the last elements.

Just as polychromy in visual arts is the process of employing many colours in sculpture, polychrony can be summarised as the craft of using different times in a composition. Just as

22 It is interesting to note that current developments in the field of artificial intelligence applied to sound synthesis have been focusing on developing a software that generates sounds on a sample-by-sample basis (Engel, Agrawal, Chen, Gulrajani, Donahue and Roberts 2019). 
polychromy depends on the position of the observer, the experience of polychrony depends on numerous external factors, not least the soundpoint of the listener.

\subsection{Interpolation: are current electroacoustic composition tools optimal for polychrony?}

The electroacoustic composition ecosystem is quite rich, but tools are seldomly developed for specific electroacoustic compositional purposes. Therefore, another question that will be left open is that of the adequacy of the current electroacoustic compositional workspace for effective polychrony. Underneath it lies the Pandora's box of representations for electroacoustic music: we shall not open it at this moment, and leave it to rest for the time being.

\section{CONCLUSION}

Expanding on an earlier remark in this text, it could be said that electroacoustic music understanding (and its evolution, analysis) is largely an introspective experience of deconstructing the cognitive processes at play during the perception of sonic units through one's perspective. There have been many explicative approaches developed that focus on the perceptual aspects of sound-based and electroacoustic music; interestingly enough, the temporal aspects are usually reduced to mere parameters. This article presented several concepts that aim to establish a temporal framework as the basis for electroacoustic music understanding.

First, instead of relying on Schaeffer's objet sonore, that inevitably comes with the underlying and limiting écoute réduite, we introduced the concept of sonic unit, which has the merits of being adaptable depending on a) the density of sonic information, and b) the listener's perspective - which I termed in this article his/her 'soundpoint'.

Second, the concept of temporal directionality and its three discrete cases - intrinsic, extrinsic and peripheral, which permits the definition of the endogenous temporal characteristics of sonic units - was introduced. Drawing on the series developed in McTaggart's approach of time, each case belongs either to a history (A-series), a set (Bseries) or a collection (C-series).

Third, temporal distancing has been described, which serves in expressing the relations between sonic units and the listener's subjectivity. It can be seen as a 'measure' of the efforts 
the listener has to make to construct his/her own coherence out of a given electroacoustic work, or how much the inner structural coherence of the work is forced onto him. ${ }^{23}$

Finally, the concept of polychrony has been introduced as a new way of characterising electroacoustic composition techniques, especially since the use of digital technology in sound and music creation. It should be stressed again that it goes beyond the stylistic limitations of granular and/or microsound composition.

Such concepts aim to highlight differences and similarities across various subgenres of electroacoustic music more clearly, by substituting the usual morphological bias with a new approach of musical time. ${ }^{24}$ Further work will therefore go into finding strategies to make these theoretical concepts operational, particularly for an analytical standpoint.

\section{REFERENCES}

Arom, S. 1985. Polyphonies et polyrythmies instrumentales dAfrique centrale. Structure et méthodologie. Paris: SELAF.

Atkinson, S. 2007. Interpretation and musical signification in acousmatic listening. Organised Sound 12(2): 113-22.

Bergson, H. 1922 [2007]. Durée et Simultanéité. Paris: Presses Universitaires de France.

Blackburn, M. 2011. The Visual Sound-Shapes of Spectromorphology: An Illustrative Guide to Composition. Organised Sound 16(1): 5-13.

Boulez, P. 1968. Penser La Musique Aujourdhui. Paris: Gonthier.

Clayton, M. 1996. Free Rhythm: Ethnomusicology and the Study of Music without Metre. Bulletin of the School of Oriental and African Studies 59(2): 323-332.

Clayton, M. 2008. Time in Indian Music: Rhythm, Metre and Form in North Indian Rāg Performance. Oxford: Oxford University Press.

Dahan, K. 2007. Surface Tensions: Dynamics of Stria. Computer Music Journal 31(3): 65-74.

Dahan, K. 2009. Emergence, Enaction et Propagation Des Dimensions Temporelles Dans Les Processus Compositionnels. In G. Mathon (ed.) Filigrane 10: Sur le rythme. Paris: Delatour.

${ }^{23}$ Of course, this process of 'negotiation' is not exclusive to electroacoustic music, and the same approach could be applied in other cases, particularly where there is no established symbolic representation system.

${ }^{24}$ Tests, discussions and observations on students suggest that these are workable analytical and pedagogical models. 
Delalande, F. 1996. Les Unités Sémiotiques Temporelles: Problématique et Essai de Définition. In L. M. Marseille (ed.) Les Unités Sémiotiques Temporelles: Elements nouveaux d'analyse musicale. Marseille: ESKA, 16-25.

Emmerson, S. (ed.) 1986. The Language of Electroacoustic Music. London: MacMillan.

Engel, J., Agrawal K. K., Chen, S., Gulrajani, I., Donahue, C. and Roberts, A. 2019.

GANSYNTH: Adversarial Neural Audio Synthesis. Proceedings of the International Conference on Learning Representations. https://arxiv.org/pdf/1902.08710.pdf

Forte, A. 1973. The Structure of Atonal Music. New York: Yale University Press.

Huron, D. 1996. Sweet Anticipation. Cambridge, MA: MIT Press.

Kayser, C. 2019. Evidence for the Rhythmic Perceptual Sampling of Auditory Scenes.

Frontiers in Human Neuroscience 13. https://doi.org/10.3389/fnhum.2019.00249.

Kramer, J. D. 1978. Moment Form in Twentieth Century Music. The Musical Quarterly 64(2): 177-94.

Kramer, J. D. 1988. The Time of Music. New York: Schirmer Books.

Kramer, J. D. (ed.) 1993. Time in Contemporary Musical Thought. Contemporary Music Review 7(2).

Landy, L. 1994. The 'Something to Hold on to Factor' in Timbral Composition.

Contemporary Music Review 10(2): 49-60.

Langer, S. K. 1942. Philosophy in a New Key: A Study in the Symbolism of Reason, Rite and Art. Cambridge, MA: Harvard University Press.

Lerdahl, F. and Jackendoff, R. 1983. A Generative Theory of Tonal Music. Cambridge, MA: MIT Press.

Leroi-Gourhan, A. 1966. Le geste et la parole, tome 2: la mémoire et les rythmes. Paris:

Albin-Michel (trans. A. Bostock-Berger. 1993. Gesture and Speech. Cambridge, MA: MIT Press).

Margulis, E. H. 2014. On Repeat: How Music Plays the Mind. New York: Oxford University Press.

McTaggart, J. E. 1908. The Unreality of Time. Mind 17(68): 457-74.

McTaggart, J. E. 1927. The Nature of Existence. Cambridge: Cambridge University Press.

Meyer, L. 1967. Music, the Arts, and Ideas. Chicago: University of Chicago Press.

Ockelford, A. and Sergeant, D. 2013. Musical Expectancy in Atonal Contexts: Musicians Perception of 'Antistructure'. Psychology of Music 41(2): 139-74. 
Patel, A. 2008. Beat-based Rhythm Processing as a Key Research Area. In A. Patel (ed.) Music, Language and the Brain. Oxford: Oxford University Press, 402-15.

Risset, J.-C. 1996. Problèmes danalyse: quelques clés pour mes premières pièces numériques, Little Boy et Mutations. Analyse en musique électroacoustique. Bourges: IMEB.

Roads, C. 2015. Composing Electronic Music: A New Aesthetic. New York: Oxford University Press.

Schaeffer, P. 1966. Traité Des Objets Musicaux. Paris: Seuil.

Schenker, H. 1935. Der freie Satz. Vienna: Universal Edition (trans and ed. E. Oster. 2001. Free Composition. New York: Pendragon Press).

Smalley, D. 1997. Spectromorphology: Explaining Sound-Shapes. Organised Sound 2(2): $107-26$.

Stiegler, B. 2018. La technique et le temps. Paris: Fayard (compiled version of 1. la faute d'Epiméthée; 2. la désorientation; 3. le temps du cinéma et la question du mal-être).

Stockhausen, K. 1963. Momentform: Neue Beziehungen zwischen Auffürungsdauer, Werkdauer und Moment. In Texte zur Musik, vol. 1. Cologne: DuMont Schauberg, 189210.

Tymoczko, D. 2011. A Geometry of Music: Harmony and Counterpoint in the Extended Common Practice. New York: Oxford University Press.

Vaggione, H. 2001. Some Ontological Remarks about Music Composition Processes. Computer Music Journal 25(1): 54-64.

Xenakis, I. 1963. Musiques Formelles, Vol. 253-254. Paris: Revue Musicale.

Xenakis, I. 1997, Kéleütha-Écrits. Paris: Larche.

\section{DISCOGRAPHY}

33EMYBW. 2019. Arthropods. Shanghai: SVBKVLT, SBKT031.

Autechre. 2003. Theme of a sudden roundabout. Draft 7.30. London: Warp, WARPCD111.

Bayle, F. 1967. Espaces Inhabitables. Paris: Magison, MGCB1400 (2000).

Cascone, K. 2003. The Bourbaki Conjecture. blackCube(). Anechoic, a0006.

Chowning, J. 2010. Stria (1977; rev. Chowning/Dahan 2010). Reconstructed version.

Dashow, J. 1987. Sequence Symbols (1984). On New Computer Music. Berlin: Wergo, WER2010-50.

Ikeda, R. 2005. Dataplex. Chemnitz: Raster-Noton, R-N068.

Loy, G. 1990. Nekyia (1980). On Computer Music Currents 5. Berlin: Wergo, WER2025-2. 
McNabb, M. 1993. Dreamsong (1978). On Michael McNabb-Dreamsong/Love in the Asylum/Mars Suite. Berlin: Wergo, WER2020-2.

Parmegiani, B. 2009. De Natura Sonorum (1975). Recollection GRM. Vienna: Mego, REGRM009.

Risset, J.-C. 1987. Mutations (1968). On Risset - Sud/Dialogues/Inharmonique/Mutations. Paris: INA-GRM, INA C1003.

Schottstaedt, W. 1988. Dinosaur Music. On Dinosaur Music: Computer Music by Chafe, Jaffe, Schottstaedt. Berlin: Wergo, WER2016-50.

Stollery, P. 2006. Onset/Offset (1996). On Un son peut en cacher un autre. Montreal: empreintes DIGITALes, IMED-0678.

Ussachevsky, V. 1999. Linear Contrasts (1958). On Vladimir Ussachevsky - Electronic and Acoustic Works 1957-1972. New York: Composers Recordings Inc., CRI CD 813.

Vaggione, H. 2004. Harrison Variations. On Jonty Harrison, Horacio Vaggione, Trevor Wishart-ETC. New York: Electronic Music Foundation, EMF CD053.

Wishart, T. 2014. Globalalia. On Trevor Wishart-Globalalia/Imago. York: Orpheus the Pantomime, OTP0066. 